\title{
Osteodistrofia fibrosa em equinos criados em pastagem de Panicum maximum cultivar Aruana: relato de casos
}

\author{
[Fibrous osteodystrophy in horses raised on Aruana (Panicum maximum) pasture: case reports] \\ B.R. Curcio $^{1}$, L.A. Lins $^{2 *}$, A.L.N. Boff ${ }^{3}$, L.M. Ribas ${ }^{1}$, C.E.W. Nogueira ${ }^{2}$ \\ ${ }^{1}$ Aluno de pós-graduação - FV- UFPel - Capão do Leão, RS \\ ${ }^{2}$ Faculdade de Veterinária - UFPel \\ Caixa Postal 354 \\ 96010-900 - Capão do Leão, RS \\ ${ }^{3}$ Médico veterinário autônomo
}

\begin{abstract}
RESUMO
Relata-se a ocorrência de osteodistrofia fibrosa em 38 equinos criados em pastagens de Panicum maximum cultivar Aruana, da raça Mangalarga Marchador, provenientes de uma propriedade localizada no estado do Paraná. No exame clínico geral, observou-se aumento bilateral e simétrico dos ossos da face e, também, aumento de volume na porção distal do rádio. A análise radiológica das áreas afetadas demonstrou redução da densidade óssea, e, na bioquímica sanguínea, 24 (63\%) animais apresentaram níveis de fósforo elevados. O exame bromatológico revelou níveis elevados de oxalato na pastagem de Aruana. Conclui-se que a ingestão de Aruana, forragem com altos níveis de oxalato, foi responsável pelo aparecimento de lesões de osteodistrofia fibrosa em equinos.
\end{abstract}

Palavras-chave: equino, osteodistrofia fibrosa, oxalato, Panicum maximum cultivar Aruana

\begin{abstract}
Fibrous osteodystrophy occurrence is reported in 38 Mangalarga Marchador horses raised on Aruana (Panicum maximum) pasture from a breeding farm in Paraná state. Clinical examination showed bilateral and symmetric increase in bones of face and an increase of volume at the radius distal portion. The radiologic analysis revealed bone density reduction in affected areas. Blood biochemist demonstrated high phosphorus levels in 24 animals (63\%). Analysis of the pasture was performed and high levels of oxalate were found in the Aruana samples. It was concluded that the ingestion of Aruana, a pasture with high oxalate levels, was responsible for the appearing of fibrous osteodystrophy lesions in horses.
\end{abstract}

Keywords: equine, fibrous osteodystrophy, oxalate, Panicum maximum, Aruana

\section{INTRODUÇÃO}

O cavalo é utilizado ao longo dos anos para diversas finalidades como tração, esporte e lazer, apresentando um importante destaque econômico. Dessa forma, a preocupação com a saúde desses animais é cada vez maior. Além das enfermidades, os cuidados com a nutrição são de fundamental importância na prevenção de doenças que, futuramente, possam comprometerlhes a performance.
Distúrbios nutricionais são responsáveis por alterações metabólicas que acarretam doenças nos diferentes sistemas do organismo. Desequilíbrios minerais, principalmente na relação cálcio e fósforo (Ca:P), causam alterações ósseas, sendo a osteodistrofia fibrosa (OF), popularmente conhecida como "cara inchada", uma das mais conhecidas (Puoli Filho et al., 1999; Hintz, 2000; Estepa et al., 2006). O principal sinal clínico da OF é o aumento dos ossos da face, geralmente bilateral e simétrico,

Recebido em 25 de setembro de 2009

Aceito em 2 de fevereiro de 2010

Autor para correspondência (corresponding author)

E-mail: lucianaalins@yahoo.com.br 
atribuído à tumefação e ao amolecimento dos ossos (Puoli Filho et al., 1999; Méndez e RietCorrea, 2007).

O cavalo apresenta o trato digestório adaptado para digerir e utilizar dietas com altos níveis de fibra vegetal, portanto utiliza as pastagens como principal fonte de alimentação. Porém, existem compostos nas pastagens que indisponibilizam certos nutrientes (Pagan, 1998). O oxalato é uma substância presente em algumas forragens que, ao ser absorvido pelo organismo, se une ao $\mathrm{Ca}$ formando oxalato de cálcio, impedindo a metabolização desse mineral pelo organismo (Puoli Filho et al., 1999; Miyazaki et al., 2003; Méndez e Riet-Correa, 2007). Em consequência da baixa absorção de $\mathrm{Ca}$, ocorre aumento na secreção do paratormônio pelas células da paratireóide, o que ocasiona hiperparatireoidismo e aumento da reabsorção óssea, com consequente substituição do tecido ósseo por tecido fibroso, caracterizando a OF (Estepa et al., 2006). Dentre as pastagens tropicais que podem produzir esse quadro, estão Setaria anceps, Cenchrus ciliaris, Panicum maximum cultivar Aruana var. trichoglume, Pennisetum clandestinum e Brachiaria sp. (Miyazaki et al., 2003; Méndez e Riet-Correa, 2007).

Este trabalho teve como objetivo relatar a ocorrência de osteodistrofia fibrosa em equinos criados em pastagem de Panicum maximum cultivar Aruana.

\section{CASUÍSTICA}

O trabalho foi realizado em uma propriedade na região de Tijuca do Sul, PR, em uma propriedade com 243 equinos da raça Mangalarga Marchador, distribuídos entre éguas, garanhões, potros com dois anos, potros de sobreano e potros lactentes. A propriedade é constituída de pastagens cultivadas, utilizadas para o pastoreio dos animais, compostas de Tifton (Cynodom sp.), Hermátria (Hermathria altissima), e Aruana (Panicum maximum) e as aguadas são naturais.

No segundo semestre de 2006, 38 animais apresentaram OF, entre seis meses e três anos de idade, todos mantidos em pastoreio no cultivo de Aruana.

Ao exame clínico geral, observou-se aumento bilateral e simétrico dos ossos da face, com redução da crista facial, o que foi confirmado na palpação. Na percussão, foi percebido som maciço. As funções vitais estavam dentro dos valores fisiológicos, com exceção da dispneia presente em nove animais. Ainda à inspeção, percebeu-se aumento de volume na porção distal do radio, caracterizando fisite, mais evidente nos animais até 11 meses de idade. Os sinais clínicos foram mais evidentes nos potros entre seis meses e um ano e meio de idade, que estavam em pastoreio na Aruana, sendo mais acentuados nos animais que permaneceram 30 dias nessa pastagem.

Para o diagnóstico definitivo de OF, foi realizada avaliação radiológica, bioquímica sanguínea e exame bromatológico das pastagens. Foi realizado exame radiológico da face de seis animais e acompanhamento radiológico dos membros de 18, em que foram observadas áreas de redução da densidade óssea nas regiões afetadas.

De acordo com os resultados da bioquímica sanguínea, a relação $\mathrm{Ca}: \mathrm{P}$ estava reduzida em 30 animais (79\%) entre os que eram mantidos nas pastagens de Aruana, e em apenas $8(21 \%)$ a relação estava dentro dos valores fisiológicos, entre 2-5, conforme citado por Lumsden et al. (1980). Em 37 animais (97\%) mantidos na pastagem de Aruana, os níveis de $\mathrm{P}$ encontraramse elevados, ou seja, acima de 2,2-4,2mg/dL (Lumsden et al., 1980). Destes, 23 animais (62\%) apresentavam os níveis de Ca dentro dos limites fisiológicos, entre 10,9-12,9mg/dL (Lumsden et al., 1980), porém a relação Ca:P foi baixa em 16 (43\%). Estes dados estão apresentados na Tab. 1. Vinte e oito $(13,7 \%)$ animais dos demais lotes, selecionados ao acaso, foram submetidos à avaliação bioquímica, e apenas dois (7\%) apresentaram níveis de $\mathrm{P}$ discretamente elevados, porém a relação $\mathrm{Ca}: \mathrm{P}$ se manteve adequada, com média geral de 3,18 (Tab. 2).

Amostras da pastagem foram colhidas $\mathrm{e}$ remetidas ao laboratório para avaliação bromatológica, no qual foram encontrados níveis de oxalato diferenciado nas pastagens. Nas amostras de Aruana, as quantidades de oxalato ficaram entre 6,15 e $6,61 \%$, enquanto nas de Tífton e Hermátria os níveis foram de $0,34 \%$ e $0,30 \%$ respectivamente. Estes resultados foram obtidos em $100 \%$ de matéria seca. 
Tabela 1. Valores de cálcio, fósforo e relação Ca:P obtidos na bioquímica sanguínea dos 38 equinos criados na pastagem de Aruana

\begin{tabular}{cccc|cc|c|c}
\hline Animal & $\begin{array}{c}\text { Cálcio } \\
(\mathrm{mg} / \mathrm{dL})\end{array}$ & $\begin{array}{c}\text { Fósforo } \\
(\mathrm{mg} / \mathrm{dL})\end{array}$ & $\begin{array}{c}\text { Relacãó } \\
\text { Ca:P }\end{array}$ & Animal & $\begin{array}{c}\text { Cálcio } \\
(\mathrm{mg} / \mathrm{dL})\end{array}$ & $\begin{array}{c}\text { Fósforo } \\
(\mathrm{mg} / \mathrm{dL})\end{array}$ & $\begin{array}{c}\text { Relação } \\
\text { Ca:P }\end{array}$ \\
\hline 01 & 12,3 & 7,64 & 1,6 & 20 & 10 & 8,16 & 1,2 \\
02 & 10,7 & 6,33 & 1,69 & 21 & 11,7 & 6,01 & 1,9 \\
03 & 9,6 & 8,47 & 1,1 & 22 & 10,8 & 10,02 & 1,07 \\
04 & 11,2 & 4,68 & 2,3 & 23 & 11,3 & 6,28 & 1,79 \\
05 & 10,6 & 5,46 & 1,9 & 24 & 10,7 & 8,19 & 1,3 \\
06 & 10,8 & 10,14 & 1,06 & 25 & 11,4 & 5,4 & 2,1 \\
07 & 10,6 & 3,5 & 3 & 26 & 11,2 & 6,77 & 1,65 \\
08 & 12,3 & 4,9 & 2,5 & 27 & 11,1 & 7,41 & 1,49 \\
09 & 11,8 & 5,45 & 2,1 & 28 & 11 & 8,21 & 1,3 \\
10 & 10,8 & 7,38 & 1,46 & 29 & 12,7 & 10,14 & 1,25 \\
11 & 13,3 & 5,81 & 2,28 & 30 & 11,9 & 5,75 & 2,06 \\
12 & 11,4 & 7,73 & 1,4 & 31 & 10,7 & 7,65 & 1,39 \\
13 & 10,6 & 7,96 & 1,3 & 32 & 10,2 & 8,32 & 1,2 \\
14 & 10,2 & 9,11 & 1,11 & 33 & 12,1 & 9,62 & 1,25 \\
15 & 14,9 & 5,56 & 2,67 & 34 & 11,4 & 8,47 & 1,3 \\
16 & 11,8 & 7,01 & 1,68 & 35 & 10,1 & 8,12 & 1,2 \\
17 & 10,4 & 10,86 & 0,96 & 36 & 13,2 & 8,27 & 1,59 \\
18 & 11,6 & 7,44 & 1,5 & 37 & 11,7 & 7,16 & 1,6 \\
19 & 11,8 & 8,18 & 1,44 & 38 & 11,6 & 8,19 & 1,4 \\
\hline
\end{tabular}

Valores superiores aos limites fisiológicos

Valores inferiores aos limites fisiológicos

Tabela 2. Valores de cálcio, fósforo e relação Ca:P obtidos na bioquímica sanguínea dos equinos criados nas pastagens de Tífton e Hermátria

\begin{tabular}{cccc|cccc}
\hline \multicolumn{4}{c|}{ Tífton } & \multicolumn{4}{c|}{ Hermátria } \\
\hline Animal & $\begin{array}{c}\text { Cálcio } \\
(\mathrm{mg} / \mathrm{dL})\end{array}$ & $\begin{array}{c}\text { Fósforo } \\
(\mathrm{mg} / \mathrm{dL})\end{array}$ & $\begin{array}{c}\text { Relação } \\
\text { Ca:P }\end{array}$ & Animal & $\begin{array}{c}\text { Cálcio } \\
(\mathrm{mg} / \mathrm{dL})\end{array}$ & $\begin{array}{c}\text { Fósforo } \\
(\mathrm{mg} / \mathrm{dL})\end{array}$ & $\begin{array}{c}\text { Relação } \\
\text { Ca:P }\end{array}$ \\
\hline 01 & 11 & 3,35 & 3,3 & 01 & 10,2 & 3,88 & 2,6 \\
02 & 10,4 & 2,72 & 3,8 & 02 & 9,9 & 3,26 & 3 \\
03 & 10,6 & 2,64 & 4 & 03 & 9,5 & 2,71 & 3,5 \\
04 & 10,3 & 2,81 & 3,7 & 04 & 10,3 & 4,17 & 2,5 \\
05 & 10,1 & 4,38 & 2,3 & 05 & 9,7 & 2,86 & 3,4 \\
06 & 9 & 3,53 & 2,5 & 06 & 10 & 4,31 & 2,3 \\
07 & 10,8 & 2,34 & 4,6 & 07 & 9,1 & 3,58 & 2,5 \\
08 & 10,4 & 2,73 & 3,8 & 08 & 11 & 3,61 & 3 \\
09 & 9,9 & 2,8 & 3,5 & 09 & 10 & 2,88 & 3,5 \\
10 & 9,8 & 3,59 & 2,7 & 10 & 9,6 & 3,48 & 2,8 \\
11 & 9,8 & 3,95 & 2,5 & 11 & 10,2 & 4,03 & 2,5 \\
12 & 10,8 & 2,83 & 3,8 & 12 & 10,3 & 3,05 & 3,4 \\
13 & 9,9 & 1,92 & 5,2 & & & & \\
14 & 10,5 & 4,28 & 2,5 & & & & \\
15 & 10,5 & 3,58 & 2,9 & & & & \\
16 & 9,1 & 2,93 & 3,1 & & & & \\
\hline
\end{tabular}

Valores superiores aos limites fisiológicos

Valores inferiores aos limites fisiológicos 


\section{DISCUSSÃO}

O principal sinal clínico da OF é o aumento dos ossos da face, geralmente bilateral e simétrico, atribuído à tumefação e ao amolecimento dos ossos, podendo causar dispneia e dificuldade de deglutição. Alterações nos ossos dos membros podem causar claudicação, incoordenação e dificuldades para caminhar e para levantar-se. Em alguns casos, há assimetria dos músculos dos membros, levando o animal a dar passos curtos e a se apoiar nas pinças. Fraturas e avulsão de ligamentos podem ocorrer durante o trabalho (Puoli Filho et al., 1999; Méndez e Riet-Correa, 2007). Neste trabalho, os sinais clínicos caracterizaram-se por aumento de volume dos ossos da face e fisite distal no rádio, melhor evidenciados nos potros de seis meses a um ano e meio de idade.

$\mathrm{Na}$ avaliação radiológica, foram observadas áreas de redução da densidade óssea nas regiões afetadas, sendo esta alteração característica da deposição de tecido fibroso na estrutura óssea, conforme descrito por Butler et al. (1993).

Os equinos necessitam da relação $\mathrm{Ca}: \mathrm{P}$ de, em média, $1,7: 1$, sendo $1,4: 1$ para cavalos em manutenção, 1,8:1 para potros em crescimento, 1,7:1 para éguas prenhes e 1,9:1 para éguas em lactação. Relações menores do que 1:1, em que a concentração de fósforo excede a de cálcio, podem prejudicar a absorção do Ca (Nutrient..., 1989). Neste estudo, $79 \%$ dos cavalos criados na pastagem de Aruana demonstraram baixa relação $\mathrm{Ca}: \mathrm{P}$, enquanto esta relação se manteve dentro dos limites fisiológicos nos animais criados nos demais cultivos.

A análise da concentração de Ca no sangue não é uma ferramenta de diagnóstico precisa, porque, em função dos mecanismos homeostáticos, a calcemia geralmente encontra-se dentro dos limites de referência. Dessa forma, a avaliação da dieta a que os animais são submetidos é uma forma mais confiável de detectar o problema (Estepa et al., 2006).

Neste estudo, foi realizada avaliação bromatológica das pastagens, em que os níveis de oxalato estiveram bastante aumentados na Aruana em relação aos demais cultivos. O oxalato presente nas pastagens, quando em concentrações maiores que $2 \%$ da matéria seca, causa redução na biodisponibilidade do $\mathrm{Ca}$ (Kienzle e Zorn, 2006). Isto é um problema comum em plantas tropicais que geralmente apresentam alta concentração de oxalato e baixa taxa de Ca (Pagan, 1998).

Foi diagnosticada OF em $100 \%$ dos cavalos mantidos em pastagem de Aruana, com base na apresentação clínica, relação $\mathrm{Ca}: \mathrm{P}$ na bioquímica sérica e concentração de cristais de oxalato obtida no exame bromatológico. Os cavalos criados nos demais cultivos não apresentaram sinais clínicos, além de demonstrarem adequada relação $\mathrm{Ca}: \mathrm{P}$ na bioquímica sérica. A pastagem de Aruana apresenta correta relação $\mathrm{Ca}: \mathrm{P}$, porém a alta concentração de cristais de oxalato em sua composição impede que esta pastagem forneça aporte mineral adequado aos cavalos. Dessa forma, foi possível demonstrar que a Aruana é uma pastagem que propicia o desenvolvimento desse distúrbio metabólico em equinos.

\section{REFERÊNCIAS BIBLIOGRÁFICAS}

BUTLER, J.A.; COLLES, C.M.; DYSON, S.J. et al. (Ed.) Clinical Radiology of the Horse. Oxford: Blackwell Scientific Publication, 1993. $549 \mathrm{p}$.

ESTEPA, J.C.; AGUILERA-TEJERO, E.; ZAFRA, R. et al. An unusual case of generalized soft-tissue mineralization in a suckling foal. Vet. Pathol., v.43, p.64-67, 2006.

HINTZ, H.F. Equine nutrition update. Proc. Am. Assoc. Equine Pract., v.46, p.62-79, 2000.

KIENZLE, E.; ZORN, N. Bioavailability of minerals in the horse. In: EUROPEAN EQUINE NUTRITION \& HEALTH CONGRESS, 3., Merelbeke, 2006. Proceedings... Merelbeke: [s.n.], 2006.

LUMSDEN, J.H.; ROWE, R.; MULLEN, K. Hematology and biochemistry reference values for the light horse. Can. J. Comp. Med., v.44, p.32-42, 1980.

MÉNDEZ, M.C.; RIET-CORREA, F. Osteodistrofia Fibrosa. In: RIET-CORREA, F.; SCHILD, A.L.; LEMOS, R.A.A. et al. (Ed.) Doenças de Ruminantes e Equídeos. Santa Maria: Pallotti, 2007. v.2, p.289-293.

MIYAZAKI, S.; YAMANAKA, N.; GURUGE, K.S. Simple capillary electrophoretic determination of soluble oxalate and nitrate in forage grasses. J. Vet. Diagn. Invest., v.15, p.480-483, 2003. 
Osteodistrofia fibrosa em eqüinos...

NUTRIENT requirements of horses. 5.ed. Washington: National Academy, 1989.

PAGAN, J.D. Forages for horses: More than just filler. In: PAGAN, J.D. (Ed) Advances in Equine Nutrition. Nottingham: Nottingham University, 1998. p.13-28.
PUOLI FILHO, J.N.P.; COSTA, C.; ARRIGONI, M.B. et. al. Suplementação mineral e mobilização de cálcio nos ossos de equinos em pastagem de Brachiaria humidicola. Pesq. Agrop. Bras., v.34, p.873-878, 1999. 